\section{TERRITÓRIO E IDENTIDADE NA REGIÃO CARBONÍFERA DO BAIXO JACUÍ/RS: O ACERVO DOCUMENTAL DA MINERAÇÃO DO ARQUIVO HISTÓRICO DO MUSEU ESTADUAL DO CARVÃO}

\author{
Territory and identity in the coalfield of Baixo Jacuí/RS: the documentary \\ collection of the mining of the historical archive of the Museu Estadual do \\ Carvão
}
Territorio y identidad en la región del carbon de Baixo Jacuí/RS: el acervo documental de la minería del archivo histórico del Museu Estadual do Carvão

\author{
Alexsandro Witkowski" \\ Valdir Jose Morigit* \\ *Mestre em Museologia e Patrimônio (PPGMUSPA/FABICO/UFRGS) - nettowski@gmail.com \\ **Pós-doutor em Memória Social (UNIRIO) e Doutor em Sociologia (USP), Professor titular do \\ DCI/FABICO/UFRGS, professor do PPGMUSPA e PPGCIN/FABICO/UFRGS - \\ valdir.morigi@gmail.com
}

Recebido em 30/06/2019. Aceito para publicação em 30/07/2019.

Versão online publicada em 10/09/2019 (http://seer.ufrgs.br/paraonde)

\begin{abstract}
Resumo:
Os municípios da região carbonífera do Baixo Jacuí/RS tiveram sua economia e sociedade forjadas a partir da extração do carvão mineral. A documentação das antigas empresas mineradoras contém informações importantes sobre o território e a construção identitária daquelas comunidades. Este acervo é reconhecido pela função social de testemunho e de referência, caracterizando-o como patrimônio documental. O objetivo central da investigação é apresentar apontamentos e reflexões sobre território e identidade a partir do cotejamento entre o processo histórico da região (documentos) e autores que trabalham com os respectivos temas.
\end{abstract}

Palavras-chave: Arquivo Histórico do Museu Estadual do Carvão. Patrimônio documental. Território e Identidade.

\begin{abstract}
:
The municipalities of the coalfield of Baixo Jacuí/RS had their economy and society forged from the extraction of mineral coal. The documentation of old mining companies contains important informations about the territory and the identity construction. This collection is recognized by social function of testimony and reference, characterizing-or as documentary heritage. The central objective of the research is to present notes and reflections about territory and identity from the comparison between the historical process of the region (documents) and authors who work with respective themes.
\end{abstract}

Key-words: Historical archive of the Museu Estadual do Carvão. Documentary heritage. Territory and identity.

\footnotetext{
Resumen:

Los municipios de la región del carbón del Baixo Jacuí/RS he tenido su economía y sociedad forjados a través de la extracción de carbón mineral. La documentación de antiguas empresas mineras contiene informaciones importantes acerca del território y la construcción de la identidad. Este acervo es reconocido por su funcion social de testimonio y referencia, caracterizándolo como patrimonio documental. El objetivo central de la investigación es presentar notas y reflexiones acerca de territorio y
} 
identidad a través de la comparación entre el proceso histórico de la región (documentos) y autores que trabajan con los respectivos temas.

Palabras-clave: Archivo histórico del Museu Estadual do Carvão. Patrimonio documental. Territorio y identidad.

\section{Introdução}

No Rio Grande do Sul, a Região Carbonífera do Baixo Jacuí compreende os municípios de Arroio dos Ratos, Barão do Triunfo, Butiá, Charqueadas, Eldorado do Sul, General Câmara, Minas do Leão, São Jerônimo e Triunfo. Esta área está compreendida na região centro-sul, com cinco municípios incluídos na região metropolitana da capital Porto Alegre: Arroio dos Ratos, Charqueadas, Eldorado do Sul, São Jerônimo e Triunfo.

Neste território, encontra-se ainda uma subdivisão: a chamada região carbonífera tradicional, formada pelos municípios onde o carvão foi descoberto e que deram origem à exploração do minério em escala industrial: Arroios dos Ratos, Butiá, Charqueadas, Minas do Leão e São Jerônimo. Todos tiveram sua economia e sociedade forjadas a partir da extração do carvão mineral (Figuras 1 e 2).

Conforme abordado nas obras clássicas de memorialistas, Dahne (1893) e Simch (1943), e de pesquisadores, Silva (2007), Speranza (2014) e Freitas (2015), o carvão mineral, no estado do Rio Grande do Sul, foi descoberto no final do século XVIII, porém somente na segunda metade do século XIX teve início a empreitada da extração industrial do minério. De 1872 a 1888 algumas empresas pioneiras dedicaram-se à extração do carvão na região, mas a partir de 1889, com a constituição da Companhia Estrada de Ferro e Minas de São Jerônimo (CEFMSJ), em Arroio os Ratos, é que teve início o considerado período áureo do carvão.

Por esta companhia foi inaugurada, em 1924, a primeira usina brasileira gerando energia elétrica a partir do carvão mineral - a Usina Termoelétrica de Arroio dos Ratos (1924-1956). Na mesma localidade onde foi instalada a usina, funcionava desde 1908 o Poço Fraternidade ou Poço 1, onde era extraído do subsolo o carvão mineral que abastecia as locomotivas, as indústrias, a usina termoelétrica local e de outras regiões, inclusive a antiga Usina do Gasômetro ${ }^{1}$ (1928-1974), hoje Centro Cultural Usina do Gasômetro, em Porto Alegre/RS.

Figura 1 - Mapa do Rio Grande do Sul: região carbonífera do Baixo Jacuí em destaque

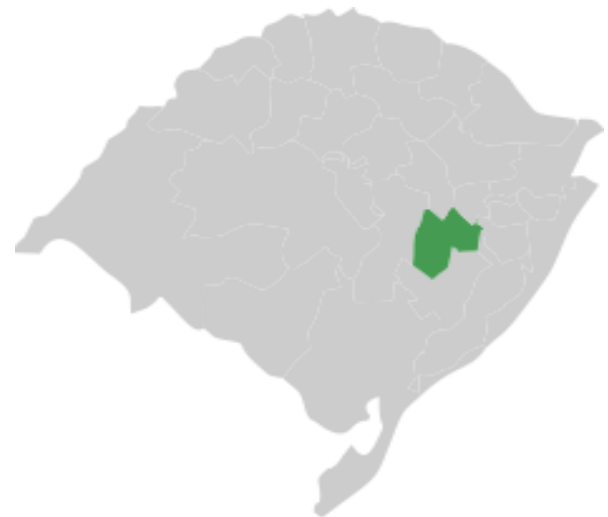

Fonte: Federação das Associações de Municípios do Rio Grande do Sul - FAMURS (2018)

\footnotetext{
${ }^{1}$ Bem tombado em 1983. Disponível em na internet: <http://www.iphae.rs.gov.br/>. Acesso em 23 jun. 2019.
} 
Figura 2 - Mapa da região carbonífera do Baixo Jacuí: os nove municípios.

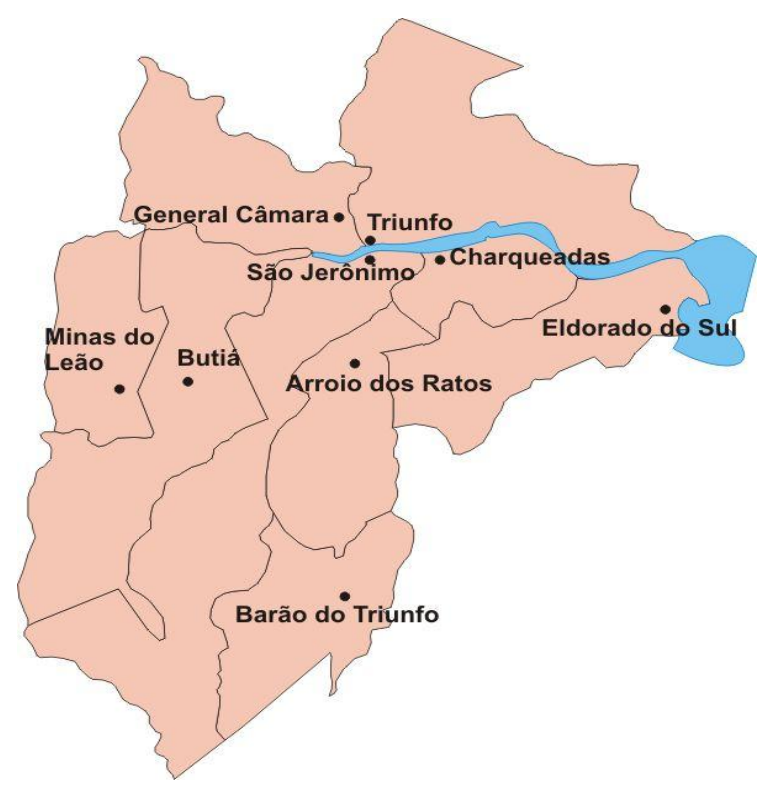

Fonte: Movimento Democrático Brasileiro, Diretório Estadual do RS - MDB/RS (2018).

O complexo industrial carbonífero de Arroio dos Ratos modificou consideravelmente o panorama econômico e social da região. O aparente bem-estar vivido pela comunidade, que dispunha de serviços essenciais tais como escolas, moradias e hospital, além de espaços de sociabilidade, esteve arraigado no paternalismo (SPERANZA, 2014, p. 68).

As marcas da indústria carbonífera continuam presentes nas comunidades da região, tanto em forma de vestígios materiais quanto imateriais, inclusive, conforme Milton Santos (1998, p. 17), em referência a dialética do território, com o controle local e remoto da parcela técnica da produção.

Neste contexto, destacam-se os remanescentes do antigo complexo industrial carbonífero do Poço 1 e Usina Termoelétrica de Arroio dos Ratos, atual complexo cultural do Museu Estadual do Carvão ${ }^{2}$ (FREITAS, 2015, p. 81). Neste espaço está localizado o acervo documental da mineração, organizado por uma equipe técnica através de projeto cultural iniciado em novembro de 2014 e finalizado em agosto de $2018^{3}$.

Hoje, a outrora massa documental das antigas empresas mineradoras está disponível à consulta pública de todo o acervo, de meados do século XIX até a década de 1990. A salvaguarda é em um prédio tombado, restaurado e requalificado para ser o Arquivo Histórico do Museu Estadual do Carvão ou Arquivo Histórico da Mineração, localizado dentro do complexo cultural do Museu Estadual do Carvão, próximo ao centro histórico do município de Arroio dos Ratos e, aproximadamente, a 54 km de Porto Alegre.

O objetivo central da investigação é apresentar apontamentos e reflexões sobre território e identidade a partir do cotejamento entre o processo histórico da região

\footnotetext{
${ }^{2}$ Bens tombados em 1986 e 1993. Disponível na internet: <http://www.iphae.rs.gov.br/>. Acesso em 23 jun. 2019.

${ }^{3}$ Projeto cultural aprovado pelo Conselho Estadual da Cultura (CEC/RS), com recursos captados através da Lei de Incentivo à Cultura (LIC): Projeto Acervo Documental da Região Carbonífera do RS. Disponível na internet: <http://www.procultura.rs.gov.br/>. Acesso em 20 set. 2018.
} 
(documentos) e autores que trabalham com os respectivos temas. A importância do acervo documental da mineração está em seu conjunto inédito de fontes primárias e secundárias (mapas, relatórios, cartas, correspondências diversas, registros, jornais, etc.) disponíveis à produção de conhecimento científico sobre o cotidiano das antigas empresas mineradoras e dos operários, especialmente dos mineiros do subsolo, conhecendo melhor sobre seus saberes e fazeres, inclusive a formação dos territórios da mineração e a construção identitária e sentimento de pertencimento desses trabalhadores.

\section{Origens do acervo documental da mineração}

$\mathrm{Na} \mathrm{O}$ acervo documental da mineração é constituído basicamente por centenas de milhares de documentos diversos expedidos ou recebidos pelas empresas mineradoras da região carbonífera do Baixo Jacuí/RS, entre 1891 e 1994. Seu volume original foi muito maior, mas por diversos motivos (sinistros, extravios, descartes indevidos, ação dos agentes biológicos, etc.) essa documentação sofreu um processo de fragmentação a partir de meados da década de 1990, quando a empresa mineradora responsável pela salvaguarda providenciava sua eliminação, prejudicando sua proveniência arquivística e organicidade.

No ano de 1996, graças a ação da comunidade local, especialmente da Associação Cultural Butiaense (ACUB), localizada no município de Butiá, foi impedido que essa massa documental fosse eliminada pela Copelmi Mineração Ltda ${ }^{4}$, empresa responsável pela documentação custodiada pelas antigas empresas mineradoras que foram incorporadas em 1964, inclusive a documentação do Consórcio Administrador de Empresas de Mineração (CADEM), responsável pela administração das duas grandes empresas mineradoras, no período de 1936 a 1964 (VIVAR et al., 2016, p. 18-19).

A preservação da massa documental acumulada da mineração, que estava em avançado estado de degradação, depositado em um ambiente impróprio no antigo Engenho Novak, em Butiá, esteve por 15 anos sob a guarda da ACUB (1996-2010) (Figuras 3 e 4).

Mas foi apenas em 2009 que se iniciou o processo de formação de um grupo de voluntários organizados para a salvaguarda adequada da documentação e disponibilizar para a consulta pública. O grupo era formado por profissionais (professores e técnicos) e acadêmicos de diversas áreas do conhecimento (História, Arquivologia, Sociologia, Biblioteconomia, entre outras) que desenvolviam pesquisas acadêmicas sobre a região carbonífera ou atuavam profissionalmente na região carbonífera ${ }^{5}$.

\footnotetext{
${ }^{4}$ A Copelmi é uma empresa centenária. Alega que sua origem inicia com a fundação da Companhia Minas de Carvão de Pedra do Arroio dos Ratos (CMCPAR), em 1883. A empresa requereu liquidação judicial em 1888 e se reorganizou com o nome de Companhia das Minas de São Jeronymo (CMSJ) em maio de 1889. A Companhia passou a se denominar CEFMSJ em setembro de 1889. Breve histórico da Copelmi:

1889: Constituição da Companhia Estrada de Ferro e Minas de São Jerônimo - CEFMSJ;

1917: Constituição da Companhia Carbonífera Rio-Grandense - CCR;

1936: Formação do CADEM - Consórcio Administrador de Empresas de Mineração: CEFMSJ (Arroio dos Ratos) e CCR (Butiá);

1941: Incorporação da CCR pela Companhia Carbonífera Minas do Butiá - CCMB;

1948: Constituição da Companhia de Pesquisas e Lavras Minerais - Copelmi;

1964: Incorporação da CEFMSJ e da CCMB pela Copelmi;

1991: Alteração da razão social para Copelmi Mineração Ltda.

${ }^{5}$ Toda documentação analisada dos projetos Uma Luz no Fim do Túnel e Acervo Documental da Região Carbonífera
} 
Após uma reunião do grupo voluntário, foi levantada a ideia de começar um projeto educativo visando à preservação da documentação como uma forma de conseguir mais apoiadores através da publicidade da documentação associada à história da região carbonífera.

Os primeiros passos dessa iniciativa incluíram a comunidade escolar pertencente aos diversos municípios da região. Surgia então o projeto Uma Luz no Fim do Túnel, um título alusivo ao trabalho do mineiro de carvão, que após uma jornada exaustiva no subsolo, no fundo escuro da mina, encontrava a luz ao sair das galerias subterrâneas (WITKOWSKI; FREITAS, 2015, p. 220-221).

Era o alerta necessário para a salvaguarda das fontes primárias que estavam em local inadequado, sem catálogo e não organizadas conforme os diversos assuntos a serem abordados sobre a mineração e o cotidiano do mineiro nas décadas iniciais do século $X X$.

\section{Figura 3 - Entrada do antigo Engenho Novak, localizado no município de Butiá/RS.}

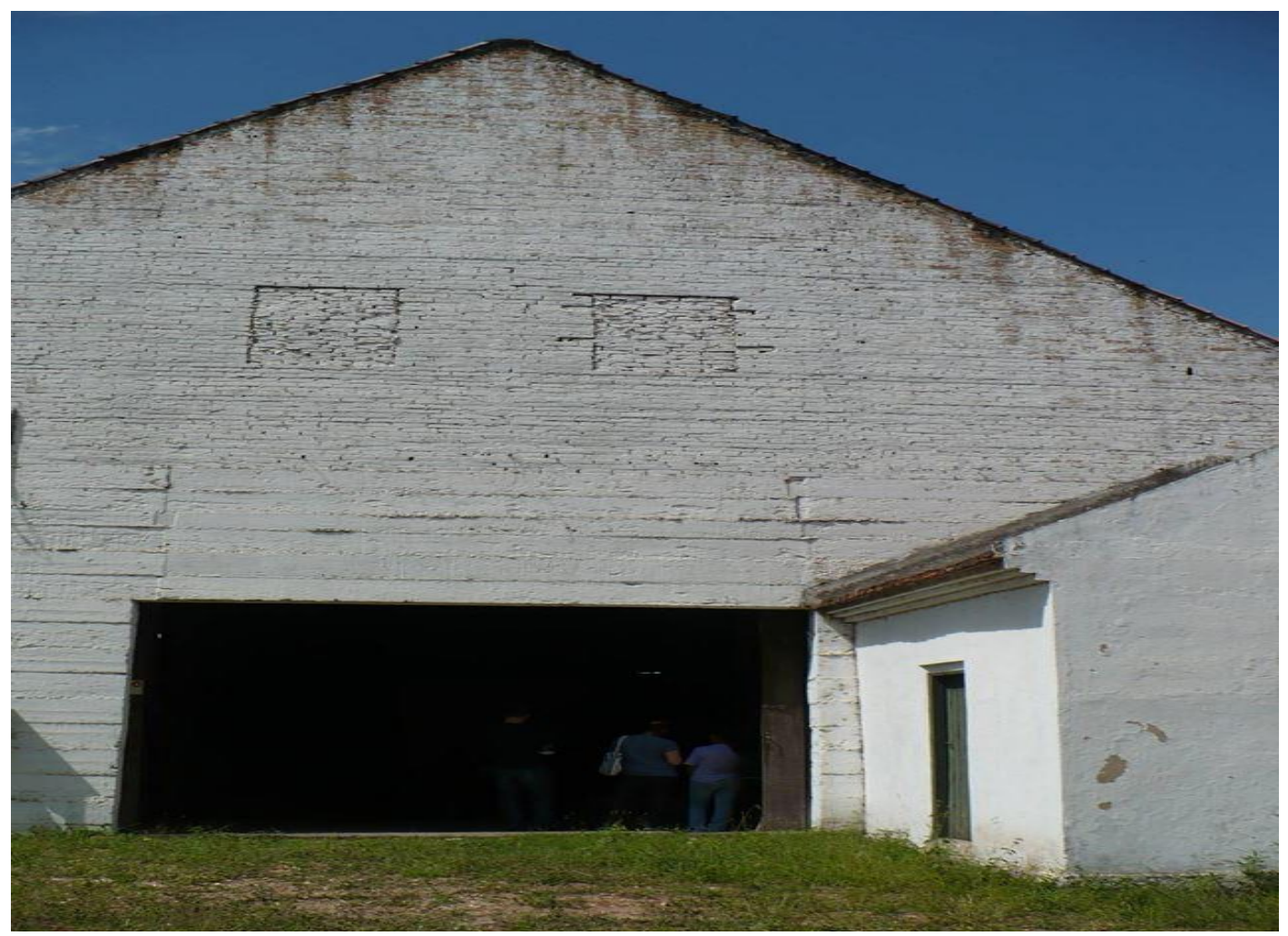

Fonte: Acervo particular do autor (2009). 
Figura 4 - Interior do antigo Engenho Novak e a massa documental das empresas mineradoras.

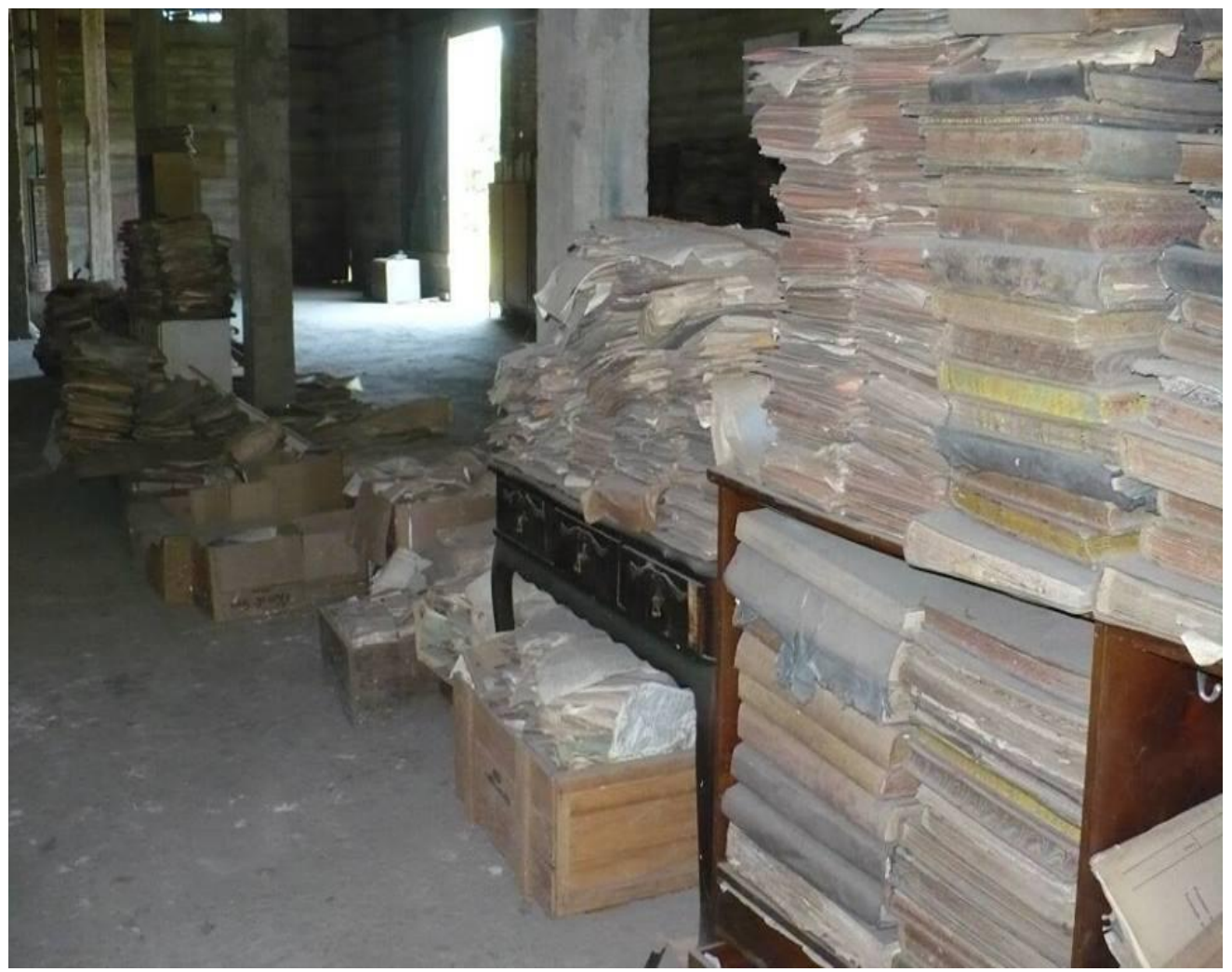

Fonte: Acervo particular do autor (2009).

A primeira etapa da ação educativa foi realizada nas dependências do Instituto Federal Sul-Rio-Grandense (IFSUL - Campus Charqueadas) no segundo semestre de 2009. O objetivo era de promover a salvaguarda da massa documental por intermédio de ações de higienização básica dos documentos e elaboração de um inventário inicial, visando à posterior construção de um banco de dados acessível ao público e ferramentas virtuais em favor da divulgação do acervo. Nessa etapa do projeto, dezenas de estudantes tanto do campus Charqueadas quanto de outras escolas e universidades da região e membros da comunidade participaram das oficinas teóricas e práticas de higienização básica e organização preliminar de documentos.

A partir dessa iniciativa desenvolvida em 2009 e 2010, no IFSUL - Campus Charqueadas, surgiram novos trabalhos, projetos e acordos. Mas agora envolvendo 0 estado do Rio Grande do Sul. Avançando em sua proposta de atuação como equipamento cultural multifacetado, em fevereiro de 2011, o Museu Estadual do Carvão acolheu o projeto Uma luz no fim do túnel.

Em maio de 2011 foi oficializado Termo de Doação com Encargos entre a Secretaria de Estado da Cultura e a Copelmi Mineração Ltda., com a finalidade de realizar oficinas de higienização básica de documentos, incluindo a doação oficial da documentação das antigas empresas de mineração ao acervo do Museu Estadual do Carvão. Em janeiro de 2012 foi assinado Acordo de Cooperação Técnica entre as partes com diversos itens, inclusive de desenvolvimento de projetos culturais que possibilitou em novembro de 2014 o projeto cultural para organização e estruturação dos fundos documentais via lei 
de incentivo à cultura (WITKOWSKI; FREITAS, 2015, p. 228-232).

\section{Museu Estadual do Carvão}

O Museu Estadual do Carvão (MCAR), órgão da Secretaria de Estado da Cultura (SEDAC/RS), tem como sua missão básica preservar o patrimônio histórico-cultural da mineração do carvão no Rio Grande do Sul, potencializando a interação das comunidades com a sua produção técnica, científica e cultural, além dos testemunhos históricos da instituição, promovendo a transformação do patrimônio em herança cultural, decorrente da apropriação e da noção de pertencimento dos cidadãos e da sociedade.

O MCAR foi oficialmente criado em 1986, através do decreto estadual $n=32.211$, de 31 de março. É essencialmente um museu histórico, patrimônio cultural tombado pelo Instituto do Patrimônio Histórico e Artístico do Estado (IPHAE/RS), em 1986 e 1993, um equipamento cultural reflexivo, de comunicação, preservação e pesquisa, pluralidade cultural e educativo, de memória e identidade, de cidadania, trabalho e meio ambiente. Atualmente o complexo cultural do MCAR possui uma área total (superfície) de $107.894,10 \mathrm{~m}^{2}$, espaço este que pertenceu à antiga CEFMSJ, hoje Copelmi Mineração Ltda.

O local é considerado um exemplar de patrimônio industrial e sítio arqueológico industrial porque ali funcionou o Poço Fraternidade ou Poço 1, aberto em 1908, e a Usina Termoelétrica de Arroio dos Ratos, inaugurada em 1924 e com término das atividades em 1956 (Figura 5). Possuí diversos prédios e remanescentes (almoxarifado, escritório, laboratório, oficinas, usina, chaminé, caldeiras do subsolo, boca do poço 1, resfriador, entre outros) da época do auge da mineração, mantendo algumas características originais e justificando seu legado cultural carbonífero (FREITAS, 2015, p. 14) (Figura 6).

Figura 5 - Complexo industrial carbonífero do Poço 1 (à direita) e Usina Termoelétrica (à esquerda) em 1935.

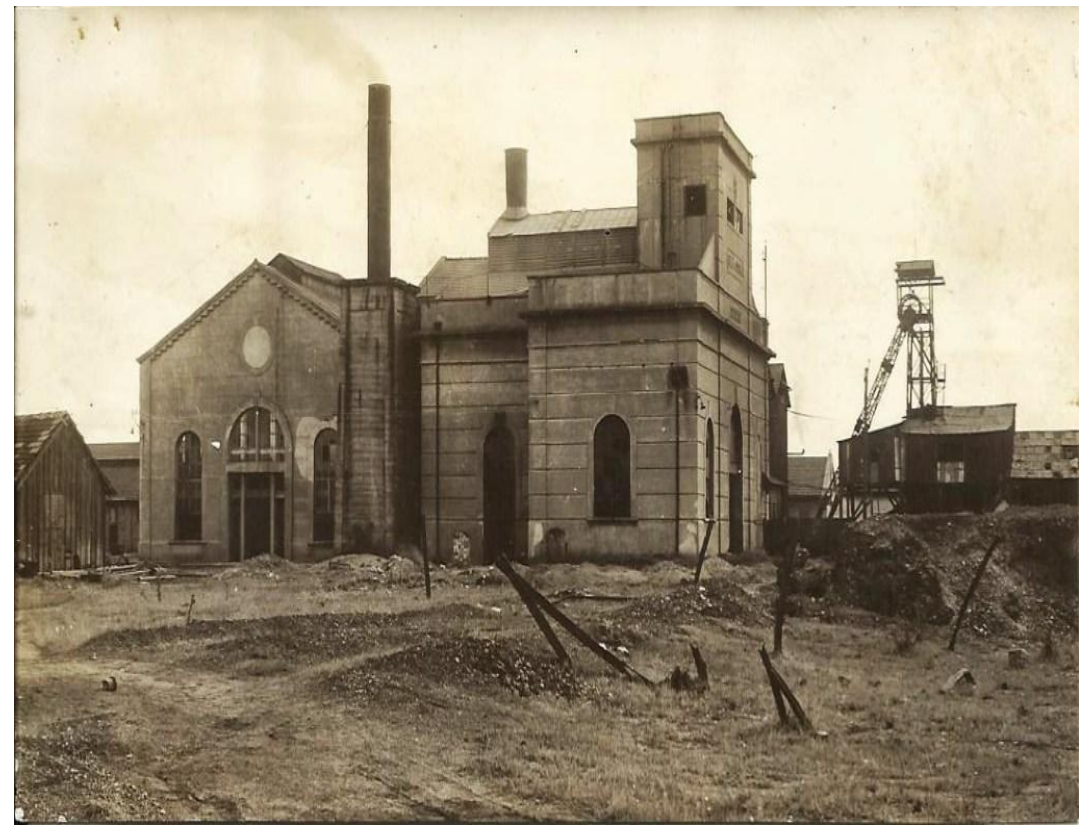

Fonte: Acervo do Museu Estadual do Carvão (2018). 
Figura 6 - Remanescentes que hoje formam o complexo cultural do Museu Estadual do Carvão, em 2014.

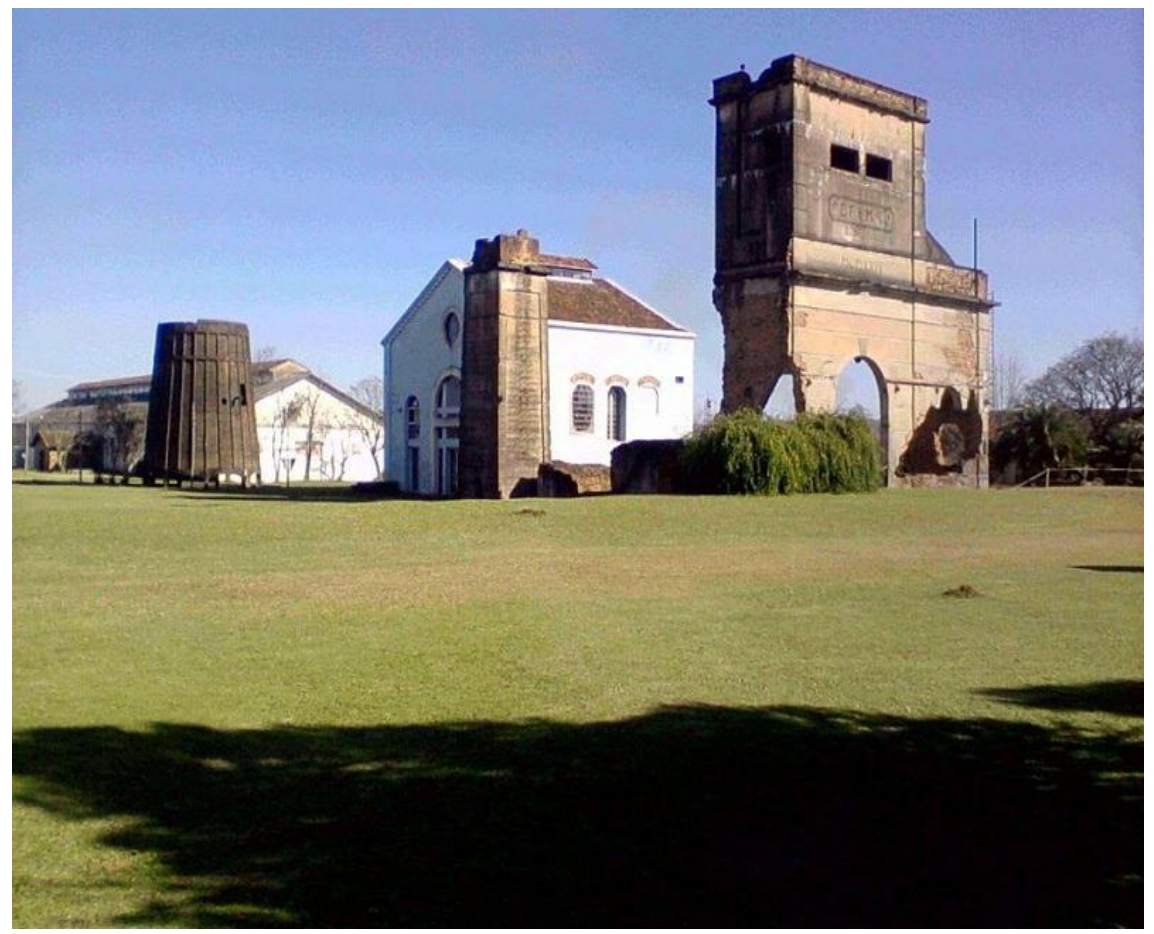

Fonte: Acervo do Museu Estadual do Carvão (2018).

Conforme a professora Maria Luiza Flores Chaves Barcellos (198?, p. 10-11), primeira Diretora do MCAR (1984-1991), a iniciativa da criação do Museu no local das ruínas da antiga Usina Termoelétrica de Arroio dos Ratos surgiu com em 1980 com Antônio Augusto Fagundes, então diretor do Museu Antropológico do Rio Grande do Sul, ao apresentar o espaço a um grupo de professores(as), do qual ela fazia parte.

Prontamente, ela iniciou as tratativas para a criação do Museu, inclusive conseguindo a doação da área de $2.126,70 \mathrm{~m}^{2}$ das ruínas da antiga usina junto à Copelmi em 1983 . Dois anos após é iniciado administrativamente o processo de tombamento do espaço e criação do Museu do Carvão. Por cerca de trinta anos (1956-1986), este espaço esteve à mercê tanto da ação humana, que dilapidava a antiga construção do complexo da Usina, tirando-lhes os tijolos e tudo o que poderia aproveitar da estrutura, quanto do tempo que se encarregava de oxidar as estruturas metálicas e cobrir com vegetação daninha o espaço outrora dinâmico (FREITAS, 2015, p. 22).

E por cerca de mais trinta anos (1986-2016) continuou - e continua - passando por um processo algumas vezes tortuoso de patrimonialização e musealização, envolvendo conflitos, disputas e ressignificações. Primeiro, a constituição de um acervo que compunha os remanescentes do antigo complexo e reunia um conjunto de valores e bens que testemunhavam momentos significativos da história industrial do Rio Grande do Sul, relacionada à formação de uma dita identidade mineira calcada no trabalho do operário mineiro, quanto relacionada à possibilidade de atratividade econômica para o município de Arroio dos Ratos e imediações.

Segundo, a utilização do complexo cultural, a partir da constatação que nos 
processos de tombamento $^{6}$ e na escolha do uso social a ser destinado ao espaço considera-se ínfima a participação da comunidade arroio-ratense, gerando uma relação deturpada até os dias atuais. Freitas (2015, p. 120) aponta que esse processo implicou em formas dúbias de apropriação da comunidade, que ora valoriza e diz ser necessária sua preservação, ora revela ser ineficiente o uso social destinado ao espaço, inclusive apelando para novos usos, muitas das vezes considerados predatórios ou danosos ao patrimônio cultural, especialmente o tangível.

$\mathrm{E}$, terceiro, do ponto de vista da busca identitária local, a preservação do espaço significa a rememoração em torno do trabalho nas minas e de todo o universo que o envolvia. Neste sentido, o acervo documental da mineração, custodiado no Arquivo Histórico da Mineração, dentro do complexo cultural do MCAR, permitirá a produção de novas reflexões sobre esses processos sociais na região do baixo Jacuí, colaborando com a produção da pesquisa científica sobre o processo histórico que marcou a região.

\section{Território e identidade: apontamentos e reflexões}

Conforme Daniel Calin (2018, p. 1-2), para o senso comum a identidade pessoal é algo hereditário, cultural desde o nascimento. Nasce-se com determinada cultura. $\mathrm{Na}$ verdade, são os agentes externos que pré determinam a cultura do indivíduo, de acordo com alguns ritos de passagens estabelecidos pelo sexo, idade, genealogia, inserção social da família, modos de produção, etc., isto é, de acordo com a formação do grupo social ou étnico a qual o indivíduo pertence. Milton Santos (1998, p. 15-16) afirma que os lugares possuem flexibilidade, não são rígidos. Mas o lugar também é a base da reprodução da vida, a tríade identidade/habitante/lugar.

O filho de um operário das minas não nascia "mineiro" em meados do século XX. No entanto, a história do indivíduo era aquela construída em função de um tempo e de uma lógica. O lugar é produto das relações humanas. E o sujeito pertence ao lugar. Naquela época, o cotidiano do trabalhador e o seu modo de vida na vila operária carbonífera (mineira) estão diretamente interligados à mina, o principal local de trabalho, às empresas carboníferas, as controladoras das vilas operárias, e ao seu pertencimento (lugar): família, relações, etc. Enfim, a importância do território para a identidade pessoal.

A identidade muda e evolui ao longo da vida, de acordo com os contextos e os momentos do ciclo de vida. A referência ao território, seja expressa por suas origens geográficas ou locais de vinculação, parece ser um importante fator de identificação. A passagem da pertença geográfica como um fator individual de construção identitária ou de territórios identitários às identidades territoriais são questões que devem ser aprofundadas e abordadas (GUÉRIN-PACE, 2004, p. 298).

Stefano Cavazza ([200?], p. 111), por exemplo, cita o estudo de Carlo Cattaneo sobre as origens da identidade italiana em muitas províncias da metade do século XIX onde a cidade é a única pátria que as pessoas conhecem e sentem. $\mathrm{Na}$ época da unificação de 1861, o sentimento de pertencer a uma entidade unitária era muito raro entre a população. As obras de Freitas (2015), Silva (2007) e Speranza (2014)

\footnotetext{
${ }^{6}$ USINA TERMOELÉTRICA (MUSEU CARVÃO 01), expediente administrativo no 44.005-19.00-SEC/85 e RESTANTE DA ÁREA QUE PERTENCEU À ANTIGA USINA, expediente administrativo no 1697-08.04-CODEC/90-0. As informações estão disponíveis em: <http://www.iphae.rs.gov.br/>. Acesso em: 9 jun. 2019. As cópias dos expedientes administrativos estão disponíveis no Museu Estadual do Carvão.
} 
apresentaram justamente um contexto sobre as origens da identidade mineira em meados do século $X X$, onde a vila operária e as minas são as únicas referências que muitas pessoas conheciam e sentiam (cotidiano).

A identidade é objeto de uma apropriação subjetiva, longa e aleatória, se formando ao longo da formação do sujeito (CALIN, 2018, p. 2-3). Não se consolida até pouco antes da adolescência, mas são sempre suscetíveis a transformações, evoluções mais positivas ou negativas, entre outros fatores. A identidade objetiva e o sentimento identitário não se sobrepõem necessariamente.

Nas pesquisas de Freitas (2015) e Speranza (2014) que abordam questões relativas à memória e à identidade mineira, especialmente as condições de vida de mineiros na extração de carvão no subsolo nas décadas de 1930 a 1950, são evidentes a existência de uma metamemória (mitologia da profissão, irmandade entre os mineiros, religiosidade ligada à devoção de Santa Bárbara - padroeira dos mineiros, etc.). Está interligada com a questão do heroísmo da categoria mineira, pois essa época da mineração de carvão também foi um tempo de muito sofrimento e exploração. A representação em torno do ofício do mineiro se materializava pela coesão social homogeneizado e sem espaços para ambiguidades e divisões.

A evolução da relação entre identidade e território depende de muitas variáveis, incluindo "a estabilidade do sistema político e sua capacidade de responder à demanda social" (CAVAZZA, [200?], p 131). A identidade é um fenômeno social de reconhecimento individual e coletivo. É construído em longo prazo, faz parte de uma genealogia. É uma narrativa, uma encenação, uma construção. São componentes essenciais das práticas e representações de cada indivíduo, mas também de qualquer ação coletiva e ideologia.

A parte (psicológica) do sujeito é que fundamenta nosso ser e a dimensão social que integramos e que contribui para nos construirmos em nosso relacionamento com os outros. Definimo-nos por múltiplas identidades que constantemente reformulam nossas relações com o espaço, territórios e outros (DI MÉO, 2002, p. 175-177). A identidade é uma representação de si mesmo. É em primeiro lugar o fato de um indivíduo e sua subjetividade (pode ser legada a lugares e coisas). Uma dinâmica pelo qual o ator social dá sentido a sua existência, ligando passado, presente e futuro: fontes de sua própria construção social e cultural. É um processo intimamente ligado à condição humana e suas inevitáveis variações sociais (DI MÉO, 2004, p. 339-341).

Para Calin (2018, p. 2-3) o sentimento de pertencimento é a dimensão social de nossa identidade, geralmente associada aos grupos sociais, de acordo com a genealogia e variáveis no processo de formação do sujeito. É pluridimensional: grupo social, religiosidade, sexualidade, etnicidade, formação profissional, participação ou influência da comunidade, influência esportiva, entre outros fatores.

O sentimento de pertencimento pode ser ainda fortemente incutido através de ritos de iniciação e/ou de passagem (exógenos) que simbolizam esta inscrição social do indivíduo, com formas mais ou menos violentas de acordo com a complexidade da sociedade. O sentido de pertença é uma questão fundamental no pensamento sobre os territórios, sentir-se como um lugar, reivindicar uma região, uma comunidade que faz sentido de pertencer.

Por exemplo, na França, em pesquisa publicada em 2003, as referências foram mais fortes com relação às cidades, depois ao departamento (estado), região e, por fim, ao 
país (GUÉRIN-PACE, 2004, p. 300-301). No caso catalão, essas identidades locais (comarcas) exaltam e reforçam a pertença a uma Catalunha da qual elas favorecem a representação unitária. As comarcas como organização territorial específica, expressam a força da identidade catalã, pois ser "[...] catalão é pertencer a um território cuja unidade é fundamental" (DI MÉO, 2004, p. 350).

No caso da região carbonífera do baixo Jacuí/RS, por exemplo, mais especificamente o caso do acervo documental da mineração, este representa um valor afetivo de memória para aqueles que tinham na indústria carbonífera (usina, mina e vila operária) seu território e horizonte. Tem um valor de documento sobre uma fase daquelas famílias das comunidades das vilas-operárias (CHOAY, 2006, p. 219-220). As vilas-operárias também receberam muitos imigrantes (ingleses, espanhóis, portugueses, poloneses, alemães, etc.) para trabalhar na mineração. Muitas famílias que lá vivem são descendentes destes imigrantes.

Em geral, o sentimento de pertencimento depende de circunstâncias que são (ou serão) importantes nos processos de mudanças de inserção social objetiva: referências no país de acolhimento, dificuldades de inserção, reações de rejeição, rupturas familiares e dos laços de localização, reorganização das estruturas familiares, mudanças familiares (números de filhos, status das crianças, etc.), entre outros fatores.

Conforme Calin (2018, p. 5-6), quando o imigrante escolheu partir, exceto nos casos de deportação, escolheu voluntariamente a ruptura que representa inevitavelmente a emigração. Mas, muitas vezes, o imigrante escolheu partir por imperiosa necessidade, determinação ou risco à vida por causa de perseguições políticas, guerras, fomes, etc. Assim, o exílio ou migração forçada ainda constituem quebras que podem ser fontes de importantes mudanças de identidades. A migração é um fator importante na determinação do lugar de pertencimento do indivíduo (GUÉRIN-PACE, 2004, p. 298299).

No caso das minas de Arroio dos Ratos, Butiá e Minas do Leão, uma categoria que reuniu imigrantes na condição de operários especializados foi a dos mineiros (SPERANZA, 2014, p. 48-49). Os dados existentes no acervo documental da mineração apontam para levas de trabalhadores que ingressaram desde a primeira década do século $X X$.

Os imigrantes mineiros foram direcionados à região carbonífera do baixo Jacuí/RS e ficaram alojados em repúblicas, isto é, as casas geminadas de alvenaria e/ou madeira e construídas pelas empresas mineradoras. Geralmente, por possuírem conhecimento técnico-especializado, esses trabalhadores ganhavam melhores cargos e funções, facilitando no seu processo de adaptação e criando um sentimento de pertencimento à localidade. Essas famílias se multiplicaram e muitos ainda permanecem nos atuais municípios da região carbonífera, pertencentes as suas respectivas comunidades.

Calin (2018, p. 8-9) afirma que a identidade em movimento possui uma significação pelas vivências, experiências, sociabilidades, entre outros fatores, necessários para a (re)construção da identidade de determinado sujeito ou até mesmo de determinado grupo social. Geralmente, esses fatores ocorrem através de processos contínuos de tensões, conflitos, relações de solidariedades, compatibilidades culturais, acolhimento, respeito, etc.

Nossa identidade é assimilada de forma múltipla, o indivíduo é engajado em um processo de construção de identidade de forma interativa e múltipla (DI MÉO, 2002, p. 
178). O sentimento de pertencimento coletivo significa uma substituição da história pessoal cultural do indivíduo (trajetória privada) por uma identidade social, isto é, uma inserção social do sujeito que não é mais assegurada por um pertencimento social imposto, mas por uma história transgeracional assumida. As dimensões sociais são dinâmicas e não estáticas, são mais voluntárias e menos impostas (CALIN, 2018, p. 910).

Pesquisando no acervo documental da mineração, no Arquivo Histórico da Mineração, conhecemos melhor o cotidiano desses mineiros de meados do século XX, multiétnicos e de várias nacionalidades (estrangeiros) e regionalidades (brasileiros e gaúchos). A formação oficial - e reconhecimento - de sindicatos dos mineiros a partir de janeiro de 1933 representa a formalização de uma identidade social já existente, mas agora legalmente habilitada para representar contra as empresas mineradoras nas disputas por melhores condições dos locais de trabalho e de salário compatível com o árduo trabalho nas minas, principalmente no subsolo (galerias) (SPERANZA, 2014, p. 48-49).

Hoje, passadas várias décadas, o mundo moderno contribui com o sentimento coletivo de pertencimento, mas depende de vários fatores, pois, apesar da influência dos Estados, da urbanização, diversificações de profissões, democratização da vida política, crescimento e visibilidade de legítimos movimentos de autodeterminação pelo mundo, etc. que contribuíram no processo de desencravar os indivíduos de suas modalidades de inserção grupal, há inúmeros sinais de resistência a tais transformações que muitas vezes não são benéficos a grupos sociais menores (minorias) ou vulneráveis. Pode representar imposições, pasteurizações culturais e crescimento de muitos movimentos reacionários (CALIN, 2018, p. 10-11).

Um efeito de imposições e uniformidades econômicas ou culturais são as afirmações de diferenciações por porta das populações ou grupos sociais e, em particular, pelo ressurgimento de identidades locais ou regionais. Conforme pesquisa realizada em 2003 na França (inquérito História de Vida, INSEE), há cada vez mais identidades fragmentadas: estar e sentir-se para agir e ser reconhecido (GUÉRIN-PACE, 2004, p. 299).

Mesmo na atualidade, onde os mineiros transformaram-se em operadores de máquinas nas minas a céu aberto, a identidade mineira parece continuar assentada nas memórias daqueles que enfrentaram os perigos da profissão, quando esta se encontrava em sua forma mais rudimentar. O desaparecimento das memórias em torno da mineração tradicional afeta os membros da categoria, mesmo estes não exercendo as mesmas atividades (FREITAS, 2015, p. 55).

\section{Arquivo Histórico da Mineração}

No segundo semestre de 2011, o antigo prédio do laboratório de análises químicas e subprodutos de carvão, localizado no complexo do Museu, foi restaurado e adaptado para ser a sede do Arquivo Histórico da Mineração (AHM) (Figura 7).

O prédio foi entregue em 17 de janeiro de 2012, em solenidade realizada no Museu Estadual do Carvão, com a assinatura do Acordo de Cooperação Técnica entre a então Secretaria de Estado da Cultura, por intermédio do Instituto do Patrimônio Histórico e Artístico do Estado, do Museu Estadual do Carvão e da Copelmi Mineração Ltda., 
objetivando a restauração das estruturas arquitetônicas do complexo do Museu Estadual do Carvão e o desenvolvimento de projetos culturais através de leis de incentivo à cultura - LIC (WITKOWSKI; FREITAS, 2015, p. 226-228) (Figura 8).

Figura 7 - Laboratório de análises químicas e subprodutos de carvão, em 1935.

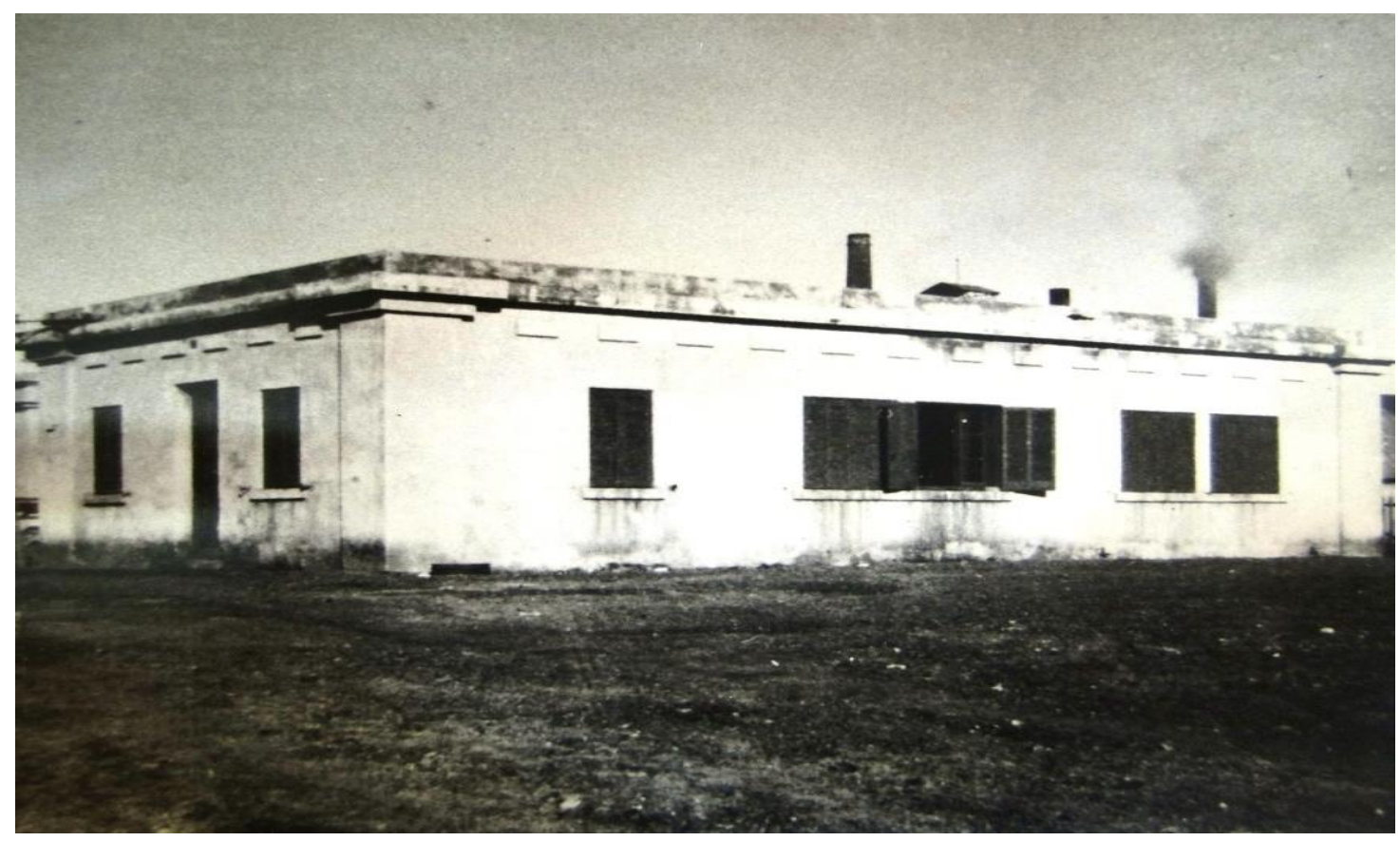

Fonte: Acervo do Museu Estadual do Carvão (2018).

Figura 8 - Hoje é o Arquivo Histórico da Mineração, no Museu Estadual do Carvão, restaurado em 2012.

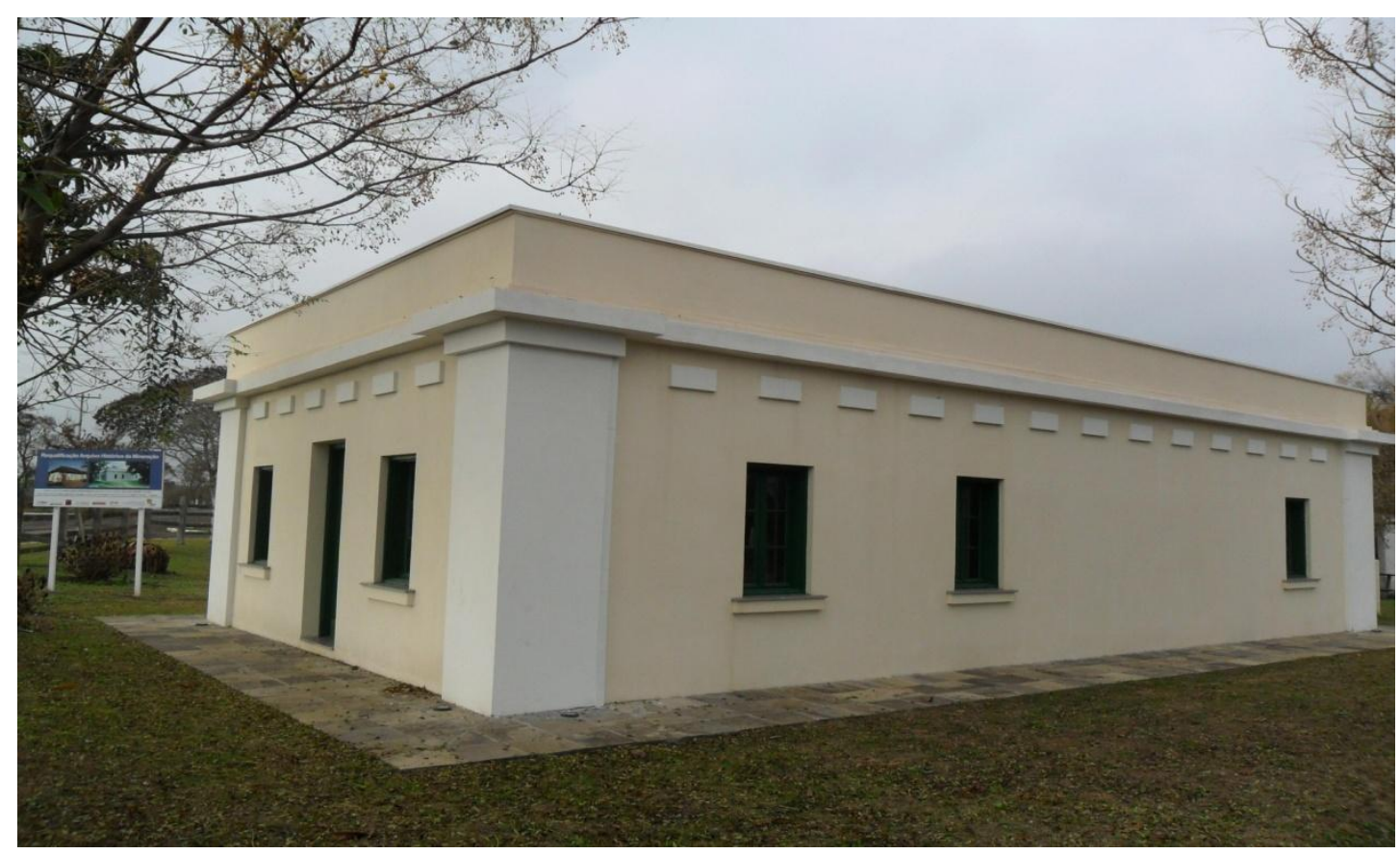

Fonte: Acervo do Museu Estadual do Carvão (2018). 
Em novembro de 2013 foi assinado novo Termo de Doação com Encargos entre a Secretaria de Estado da Cultura e a Copelmi Mineração Ltda., prevendo a doação de R\$ 152 mil (cento e cinquenta e dois mil reais) ao Museu Estadual do Carvão para a aquisição do mobiliário e equipamentos necessários para o prédio do Arquivo Histórico da Mineração (AHM). Acrescenta-se ainda a contratação de mão de obra especializada para organizar a massa documental, preparando-a para torná-la em acervo documental. (Figura 9)

Figura 9 - Interior do Arquivo Histórico da Mineração, com a documentação organizada: conclusão do projeto cultural, em 2018.

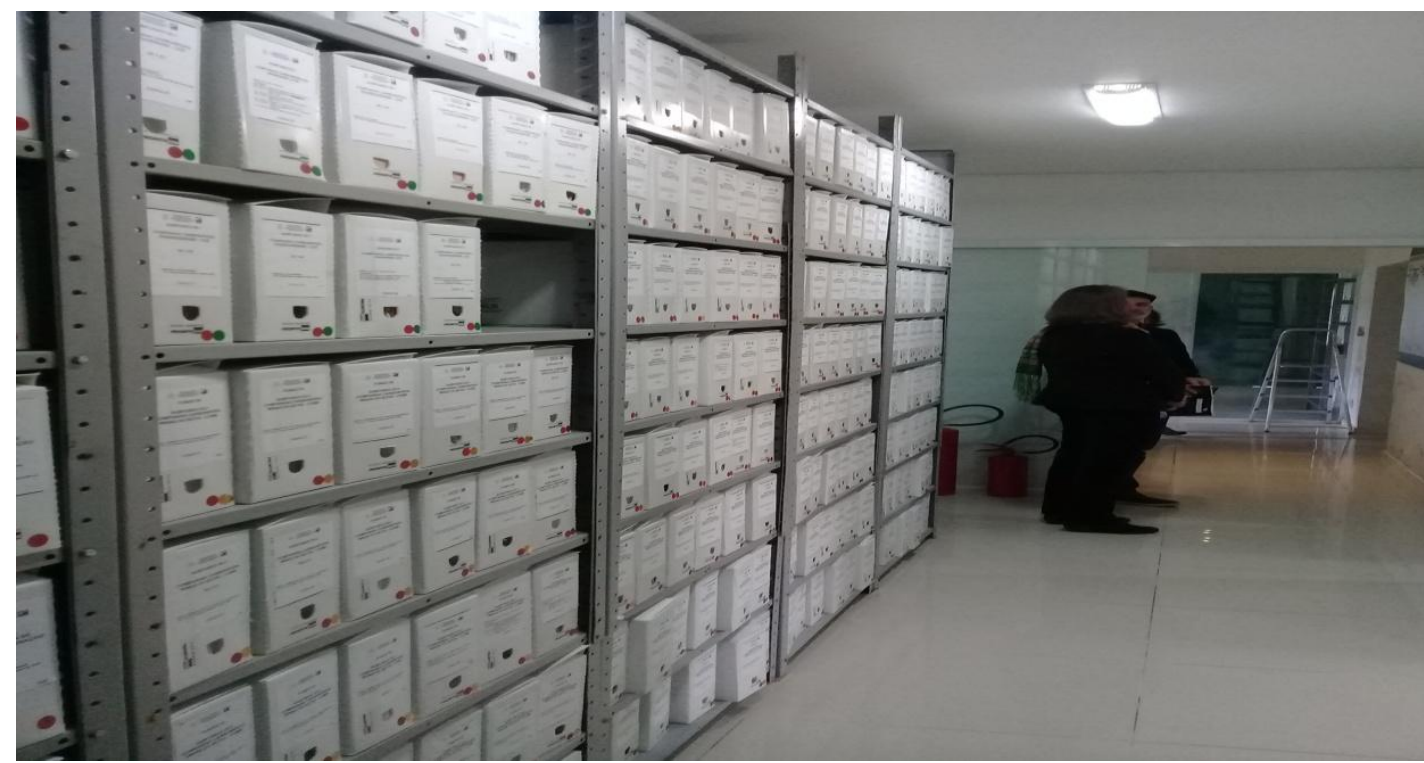

Fonte: Acervo particular do autor (2018).

Também foi providenciado o recolhimento e a identificação do restante da documentação que ainda estava na Mina do Recreio, em Butiá/RS. Em abril de 2014 toda a documentação já estava no prédio do AHM. Este fato proporcionou consideravelmente a brevidade na higienização, identificação preliminar e acondicionamento dos conjuntos documentais em seis meses de atividades.

Foram adquiridos equipamentos e mobiliários específicos para o armazenamento e conservação dos documentos (caixas-arquivo, estantes de aço, mesas higienizadoras, desumidificadores e aparelhos de ar-condicionado split). A equipe contratada para organizar a massa documental era formada inicialmente por duas acadêmicas do oitavo semestre de Arquivologia (UFRGS) e por cinco profissionais de História da região carbonífera, sob a supervisão da ONG Arquivistas sem Fronteiras do Brasil (AsF-Brasil) e SEDAC/RS. Aproximadamente o equivalente a 1.000 (mil) caixas-arquivo de documentos passaram pelo processo de higienização básica (mecânica). Em maio de 2014 a primeira etapa da nova fase do projeto estava concluída (WITKOWSKI; FREITAS, 2015, p. 231-232).

A segunda etapa teve início com o projeto cultural Acervo Documental da Região Carbonífera RS, através da lei de incentivo a cultura, apresentado pelo produtor cultural Surya Projetos e com patrocínio da Copelmi, iniciado em novembro de 2014 no Museu Estadual do Carvão. O objetivo principal foi identificar, registrar e desenvolver ações 
relacionadas à documentação da atividade mineradora, bem como às referências culturais da região mineradora do Baixo Jacuí, especialmente em Arroio dos Ratos, Butiá, Charqueadas e Minas do Leão.

As três etapas concluídas foram: 1) higienização qualificada dos documentos; 2) organização dos documentos conforme Plano de Classificação de Documentos (PCD), identificação preliminar das tipologias documentais (ofícios, correspondências, mapas, etc.), registro dos documentos em instrumento específico (não-digital), descrição sumária dos conjuntos documentais; e 3) acondicionamento definitivo dos documentos em caixas específicas para este fim. A execução do projeto foi realizada pela AsF-Brasil, com anuência do Instituto do Patrimônio Histórico e Artístico do Estado do Rio Grande do Sul (IPHAE/RS).

$\mathrm{Na}$ terceira etapa do processo de recuperação da documentação, que constitui o Arquivo Histórico da Mineração, foi realizada entre 2016 e 2018, onde os documentos foram classificados e colocados parcialmente (recorte: 1891 a 1936) para consulta do público em geral, em dezembro de 2016. As atividades de higienização foram refeitas e a organização da documentação avançou com a pesquisa histórica e análise tipológica para a elaboração de instrumentos de busca e nova organização física do acervo documental. A conclusão do projeto foi em outubro de 2018, com a disponibilização de toda documentação para pesquisa e difusão de informações, com foco nas atividades das empresas mineradoras e o cotidiano das vilas-operárias da região carbonífera do baixo Jacuí.

Posteriormente, em novo projeto cultural a ser desenvolvido, pretende-se realizar o Inventário Nacional de Referências Culturais (INRC) nos municípios da região carbonífera para identificar as principais manifestações culturais daquelas comunidades, as quais configuram o patrimônio imaterial (intangível). Assim, serão recolhidos registros bibliográficos, documentais e de depoimentos orais que possibilitem indicações de ofícios (saberes e fazeres), lugares, celebrações, formas de expressão, de resistência à exploração e de solidariedade que são singulares, isto é, característicos da cultura vivida durante décadas pelas comunidades cujas trajetórias estão relacionadas aos ofícios da mineração carbonífera.

Pretende-se, além da constituição de um patrimônio documental da mineração custodiado pelo Museu Estadual do Carvão, mais especificamente no Arquivo Histórico da Mineração, desenvolver um projeto cultural que valorize uma parte importante da história destas comunidades, a história da mineração e de seus personagens.

\section{6 acervo documental da mineração como patrimônio cultural}

Este breve ensaio justifica-se, sobretudo, pela necessidade de refletir sobre a importância da preservação do acervo documental da mineração no Arquivo Histórico da Mineração. Os documentos devem ser preservados o mais próximo possível do local que o gerou ou que influenciou sua produção (territorialidade). Neste caso, o Museu Estadual do Carvão, outrora complexo industrial carbonífero (1908-1956), é o local adequado para a salvaguarda deste importante patrimônio documental. Em geral, a documentação foi gerada pelo consórcio (CADEM) e pelas empresas mineradoras na baliza geográfica da região carbonífera do baixo Jacuí, entre meados da década de 1890 até meados da década de 1990, principalmente no período do auge da mineração: décadas de 1930 a 1950. 
Assim, o complexo cultural do Museu Estadual do Carvão se torna em um local onde se cristaliza e se refugia a memória, pois preservar, requalificar e/ou restaurar uma estrutura arquitetônica ou um acervo, que testemunhou as atividades cotidianas do homem de diferentes segmentos sociais, é forma mais coerente e democrática de preservar o patrimônio e os seus vestígios, restos e testemunhos do que já passou (LUPORINI, 2000, p. 206).

A preservação do acervo documental da mineração no Arquivo Histórico da Mineração está relacionada com sua importância à história, memória e patrimônio cultural da região carbonífera. O local também é considerado um exemplar de patrimônio industrial e sítio arqueológico industrial. Enfim, o lugar de memória é um espaço e um movimento que articula memória e história, pois intencionalmente se busca preservar os vestígios, impedindo a ação do esquecimento. O acervo documental da mineração vai agregar documentos importantíssimos para historiadores e demais pesquisadores investigarem a importância não só do Museu, mas de outros bens patrimoniais da região: temporalidades, legitimidades, revalorização de heranças do passado pelo presente, reconstruções históricas, entre outros.

Conforme Dal Bó e Machado (2000, p. 269-273), de uma forma mais ampla, o patrimônio cultural pode ser definido como bens e valores materiais e/ou imateriais, transmitidos por herança às gerações futuras na trajetória de uma comunidade. É o conjunto de manifestações culturais. Assim, a história está relacionada ao patrimônio ao atribuir um valor histórico, o que pressupõe a compreensão da escolha pela sociedade do patrimônio escolhido, ou seja, a participação e importância da sociedade civil na - e para a - preservação do patrimônio.

Mas, antes de tudo, os autores lembram que é necessário que a sociedade seja estimulada a refletir e valorizar seu patrimônio, criando um sentimento de apropriação e de pertencimento com o seu local de convivência através da leitura do mundo que o rodeia, levando à compreensão do universo sociocultural e da trajetória espaço-temporal em que está inserido. A ressignificação de patrimônio, do valor econômico para a sua referência cultural, ampliou sua territoriedade: sentimentos de pertencimento e apropriação de uma comunidade.

Diante destas perspectivas, sob o ponto de vista da sustentabilidade do patrimônio cultural representativo do auge da indústria carbonífera, neste caso, o acervo documental da mineração, o patrimônio cultural é um quadro, uma moldura para o desenvolvimento, e um território que representa o produto de toda uma história natural e humana. Mas também possui as condições de conflitos decorrentes de sua história usos, desusos e ressignificações. E todo território determinado sem o respeito por seus componentes patrimoniais não poderá servir de base para um desenvolvimento local equilibrado e sustentável (VARINE, 2012, p. 35-59).

Conforme a promotora Ana Maria Moreira Marchesan, da Promotoria de Justiça de Defesa do Meio Ambiente de Porto Alegre, em sua obra A tutela do patrimônio cultural sob o enfoque do direito ambiental (2007, p. 14), ontológica e constitucionalmente, cultura e meio ambiente são fatores integrantes de uma ordem social comprometida com a qualidade de vida. O patrimônio cultural é reconhecido como função social de testemunho e como referência, assim, possui um valor de elo entre o bem, que é o espaço dotado de valor cultural, e o espaço-tempo no qual ele se produziu. O patrimônio cultural serve como uma espécie de alicerce sobre o qual a civilização como um todo se edifica e evolui (MARCHESAN, 2007, p. 46-49). 
Tendo em vista estas considerações, afirma-se que o direito ao passado se traduz na emergência da preservação do patrimônio cultural, cuja função social, conforme o caso do acervo documental da mineração (memória, história e patrimônio), é servir a todos os grupos sociais. Ao tratar do patrimônio cultural relaciona-se diretamente ao meio ambiente cultural. Este é inclusive tutelado especificamente pelos artigos 215, 216 e 225 da Constituição Federal Brasileira de 1988. (BRASIL, 1988).

Destacamos novamente que o patrimônio cultural é um conceito amplo que não envolve apenas o valor histórico dos bens. Comumente observa-se um olhar reducionista em relação ao patrimônio cultural, atrelando-o apenas à questão do valor histórico, quando este abarca também questões que envolvem a memória e a identidade dos diversos grupos sociais, pois as camadas populares, com suas personagens e fatos, também fazem parte do motor que faz girar a história.

A preservação do patrimônio cultural trata-se de uma luta em favor da cidadania. Protegê-lo, além do respaldo constitucional, é exercer nosso papel de cidadão. É dever do Poder Público e da coletividade a defesa do meio ambiente e do patrimônio cultural, preservando-os para as presentes e futuras gerações, garantia de fruição das obras do passado pelas gerações vindouras. Os espaços de memória e os lugares comuns da vida cotidiana são os melhores testemunhos das genuínas estruturas culturais e sociais do passado e do presente.

De acordo com Marcos Paulo de Souza Miranda, promotor de Justiça em Minas Gerais, na obra Lei do tombamento comentada: Decreto-Lei n. 25/1937 - doutrina, jurisprudência e normas complementares (2014, p. 09), o Superior Tribunal de Justiça tem realçado o dever de proteção ao patrimônio cultural e o alcance protetivo do Decreto-Lei no 25/1937. Com a nova ordem constitucional vigente, basta que os bens sejam portadores de referência à identidade, à ação, à memória dos diferentes grupos formadores da sociedade brasileira, para que eles possam integrar ao patrimônio cultural brasileiro, não prevalecendo mais os critérios de memorialidade e monumentalidade.

Por fim, de acordo com Possamai (2008, p. 213), o atual profissional da história deve estar assentado sobre um tripé: pesquisa, ensino e ação cultural. Deve apropriarse de conceitos como memória, patrimônio, documento, museu, arquivo, entre outros. Nesse sentido, é preciso conhecer (memória coletiva, história oral, documentos, etc.), proteger (leis, regimentos, ações da sociedade civil, etc.), conservar (ação constante) e promover (educação patrimonial, ações educativas, difusão, etc.) o patrimônio cultural.

\section{Considerações finais}

Há muitos desafios envolvidos na aproximação entre comunidades e museus e arquivos (lugares de memória). Ocorre que muitas vezes imersos numa visão romântica, esquece-se dos inúmeros entraves para esta aproximação, encontrados tanto nas instituições quanto dentro das comunidades. A falta de diálogo, que gera a incompreensão acerca da missão dos museus e arquivos na sociedade, destaca-se entre as questões problemáticas proeminentes nesta situação. A partir daí observa-se a forma inapropriada de usos, promovidos muitas vezes pelos próprios agentes públicos, que se destacam por sua ação pouco ou nada reflexiva, predatória ou de acordo com interesses particulares de alguns grupos sociais.

O Museu Estadual do Carvão tem como missão básica (função social) preservar o 
patrimônio histórico-cultural da mineração do carvão no Rio Grande do Sul. Amparandose no aporte teórico existente sobre o tema do patrimônio e na legislação vigente em defesa do patrimônio cultural, argumenta-se que o espaço territorial do Museu não é um tradicional parque de eventos e seu complexo não deve ser utilizado para atividades que não dialogam com a sua missão, que sejam predatórios ou coloquem em risco as estruturas arquitetônicas deste importante sítio arqueológico industrial do país, referência e testemunho de uma fase importante da história do Rio Grande do Sul e do Brasil.

O conteúdo do acervo documental da mineração está diretamente identificado ao contexto histórico da região, portanto, relacionado ao complexo cultural do Museu Estadual do Carvão. É o local público adequado para que o material possa ser consultado pela comunidade e demais interessados na história da região carbonífera, considerando seus relevantes valores patrimoniais intangíveis (ofício do mineiro do subsolo, por exemplo) e tangíveis: histórico industrial, artístico, documental, arqueológico industrial e natural (ambiental).

O Museu não está isolado, faz parte de um conjunto patrimonial urbano que merece um estudo técnico para ampliação do tombamento: arruamentos (Avenida Espanha, Largo dos Mineiros, etc.), prédios históricos (Hospital Sarmento Leite, sede do EC Guarani, sede do clube negro Tesouras, remanescentes das casas geminadas dos mineiros, igrejas, escolas, etc.) e outros locais que são provas de testemunho e referência da mineração no século XIX e meados do século XX.

O complexo cultural possui um potencial à pesquisa científica em várias áreas do conhecimento, às ações culturais em patrimônio e educação patrimonial, à realização de eventos culturais reflexivos que respeitem os componentes patrimoniais, ao desenvolvimento local sustentável com geração de renda, ao turismo cultural, etc. Portanto, graças ao acervo documental da mineração, o Museu hoje tem uma potencialidade e garantia de fruição do complexo cultural e de seus acervos às gerações vindouras, aparado com a legislação vigente em defesa e promoção do patrimônio cultural, e, concomitantemente, trabalhando com os problemas das comunidades envolvidas no processo.

\section{Referências}

BARCELLOS, Maria Luiza Chaves. Museu do Carvão: restaurando ruínas e memórias. Revista Pampeana, [S.I.: s.n.], p. 10-11, [198-?].

BRASIL. Constituição Federal de 1988: artigos 215, 216 e 225. Disponível na Internet: <http://www.planalto.gov.br/ccivil 03/>. Acesso em 15 set. 2018.

CALIN, Daniel. Construção identitária e sentimento de pertencimento. Traduzido do francês por Rosa Maria Vieira Medeiros, [S.I.: s.n.], 2018. 12 p.

CAVAZZA, Stefano. Território e identidade: uma perspectiva italiana. Traduzido do italiano por Eva Kempinski, [S.I.: s.n., 200?]. P. 109-131.

CHOAY, Francoise. A alegoria do patrimônio. 3. ed. São Paulo: UNESP, 2006. 288 p.

DAHNE, E. S. Eugenio. A mineração de carvão e as concessões da companhia no Estado do Rio Grande do Sul. Porto Alegre: Companhia Estrada de Ferro e Minas de São Jeronymo; Estabelecimento typographico de Gundlanch \& C., 1893. 131 p. 
DAL BÓ, Juventino; MACHADO, Maria Beatriz Pinheiro. Memória, Educação e Cidadania. Ciências \& Letras, Porto Alegre, n. 27, p. 259-276, jan./ jun. 2000.

DI MÉO, Guy. Componentes espaciais, formas e processos geográficos de identidades. Anais da Geografia, v. 113, n. 638-639, p. 339-362, 2004.

Identidade: uma mediação essencial da relação espaço / sociedade. Geocarrefour, v. 77, n. 2, p. 175-184, 2002.

FREITAS, Tassiane Melo de. De complexo carbonífero a museu: o processo de patrimonialização dos remanescentes do antigo complexo carbonífero de Arroio dos Ratos, Rio Grande do Sul, Brasil (1983 - 1994). 2015. 202 f. Dissertação (Mestrado em Memória Social e Patrimônio Cultural) - Instituto de Ciências Humanas. Universidade Federal de Pelotas, Pelotas, RS, 2015.

GUÉRIN-PACE, France. Sentimento de pertencimento e território. [S.I.: s.n.], 2004. $11 \mathrm{p}$.

LUPORINI, Teresa Jussara. Lugares da memória: políticas pela preservação do patrimônio cultural. Ciências \& Letras, Porto Alegre, n. 27, p. 205-217, jan.-jun. 2000.

MARCHESAN, Ana Maria Moreira. A tutela do patrimônio cultural sob o enfoque do direito ambiental. Porto Alegre: Livraria do Advogado, 2007. 317 p.

MIRANDA, Marcos Paulo de Souza. Lei do tombamento comentada: Decreto-Lei n. 25/1937 - doutrina, jurisprudência e normas complementares. Belo Horizonte: Del Rey, 2014. 286 p.

POSSAMAI, Zita Rosane. O ofício da História e novos espaços de atuação profissional. Anos 90, Porto Alegre, v. 15, n. 28, p. 201-218, dez. 2008.

SANTOS, Milton. O retorno do território. In: SANTOS, Milton; SOUZA, Maria Adélia A. de; SILVEIRA, Maria Laura. (Org.). Território, Globalização e Fragmentação. 4. ed. São Paulo: Hucitec, 1998. P. 15-20.

SILVA, Cristina Ennes da. Nas profundezas da terra: um estudo sobre a região carbonífera do Rio Grande do Sul. 2007. 380 f. Tese (Doutorado em História) Programa de Pós-Graduação em História. Pontifícia Universidade Católica do Rio Grande do Sul. Porto Alegre, RS, 2007.

SIMCH, Carlos Alfredo. Monografia de São Jerônimo. Porto Alegre: Livraria Andradas, 1943. $386 \mathrm{p}$.

SPERANZA, Clarice Gontarski. Cavando direitos: as leis trabalhistas e os conflitos entre os mineiros de carvão e seus patrões no Rio Grande do Sul (1940-1954). São Leopoldo: Oikos; Porto Alegre: ANPUH-RS, 2014. 295 p.

VARINE, Hugues de. As raízes do futuro: o patrimônio a serviço do desenvolvimento local. Porto Alegre: Medianiz, 2012. 256 p.

VIVAR, Jorge Eduardo Enriquez; SIMÕES, Sílvia; COUGO JÚNIOR, Francisco Alcides. Museu Estadual do Carvão: guia do Arquivo Histórico (1891-1936). Porto Alegre: Arquivistas Sem Fronteiras, 2016. 130 p.

WITKOWSKI, Alexsandro; FREITAS, Tassiane Mélo de. As ações educativas do Museu Estadual do Carvão - Arroio dos Ratos/RS. In: FRAGA, Hilda Jaqueline de; CARDOSO, Claudira do Socorro Cirino; QUEVEDO, Éverton Reis; BARROSO, Véra Lucia Maciel; 
SOUZA, Renata Cássia Andreoni de. Experimentações em lugares de memória: ações educativas e patrimônios. Porto Alegre: Selbach \& autores associados, 2015. P. 216-238. 